\title{
Regulation of HepG2 Fat Metabolism by IL1 $\beta$ and IL1 Receptor Antagonist
}

\author{
Susmita Chandra \\ Department of Biotechnology, Maulana Abul Kalam Azad University of Technology, West Bengal, India \\ Email address: \\ Susmitachandra2506@gmail.com

\section{To cite this article:} \\ Susmita Chandra. Regulation of HepG2 Fat Metabolism by IL1 $\beta$ and IL1 Receptor Antagonist. Cancer Research Journal. \\ Vol. 5, No. 4, 2017, pp. 24-34. doi: 10.11648/j.crj.20170504.11
}

Received: December 7, 2017; Accepted: December 22, 2017; Published: January 16, 2018

\begin{abstract}
Non-alcoholic fatty liver disease (NAFLD) is the major cause of steatohepatitis, cirrhosis and hepatocellular carcinoma. High saturated fat rich diet is one of the known causes of NAFLD. Non-Alcoholic liver disease NAFLD is characterized by steatosis and upregulation of different proinflammatory cytokines, like caspase-1 dependant IL1 $\beta$, type I IL1 receptor (IL1R1), and IL1 receptor antagonist (IL1Ra). Till date there is no proper treatment option available for NASH except management of obesity and food intake. Anti inflammatory drugs are used as a treatment option in atherosclerosis, where inflammatory response plays an important role. Keeping a similarity in mind the recombinant IL1Ra and inflammatory cytokine IL1 $\beta$ was tested as treatmet option for high fat condition in Palmitate treated HepG2 cells. The lipid metabolism pathways were tested with a purchased recombinant product as well as with THP1 and its macrophage extracted product. The major outcome was removal of storage fat from the cells by increasing the beta oxidation level. So the conclusion was that IL1Ra can play a major role in controlling the accumulated fatty level in liver cells.
\end{abstract}

Keywords: NAFLD, IL1 $\beta$, IL1Ra, THP1-Monocyte and Macrophage

\section{Introduction}

Non-alcoholic fatty liver disease (NAFLD) is recognised as the most common cause of liver dysfunction worldwide and has emerged as a major public health issue [1]. Fatty liver disease encompasses a spectrum of hepatic pathology, ranging from simple steatosis to non-alcoholic steatohepatitis, cirrhosis, hepatocellular carcinoma and endstage liver disease [2]. Moreover, NAFLD is often associated with other metabolic conditions, such as diabetes mellitus type 2, dyslipidemia and visceral obesity [3]. Steatosis occurs when the rate of import or synthesis of fatty acids by hepatocytes exceeds the rate of export or catabolism [4]. Recent evidence shows that esterification of FFA to triglyceride is a protective mechanism which limits hepatocellular exposure to FFA induced lipotoxicity, Currently, there is increasing evidence that genetic as well as environmental factors, like food habit, life style changes play important roles in the progression of NAFLD [4, 5].

In particular, non-alcoholic steatohepatitis is characterized by a marked activation of inflammatory responses and the upregulation of several soluble inflammatory mediators [6, 7]. The most inflammed condition in NAFLD gradually evolves towards chronic and serious liver diseases. Kupffer cells plays a very prominent role in modulating the different stages of the disease [8]. It has been observed that chronic liver injury results in forced proliferation of differentiated liver resident quiescent stellate cells. It is considered as one of the major pathogenic mechanistic cause underlying behind development of steatohepatities [9, 10]. Liver inflammation is also found to be resulted from inercellular fat deposition. Various cytokines and chemokines are thought to play an active and pivotal role in progression of NAFLD into steatosis and are considered as potential therapeutic targets [11].

Several mechanisms were proposed to explain how obesity and inflammation increases NAFLD risk, including the prevalence of type II diabetes and insulin-resistance amongst obese individuals, which result in elevated circulating concentrations of insulin and insulin-like growth factor 1 (IGF-1), as well as increased production of cytokines by adipose tissue or kupffer cells [10, 11].

Another mechanism that accounts for the tumor promoting effect of obesity is the low grade inflammatory response [13], 
which results in elevated production of cytokines, such as TNF alpha and IL-6, which was found to positively correlate with progression of chronic fatty liver diseases in humans [14].

Non-Alcoholic liver disease NAFLD is also characterized by steatosis and upregulation of different proinflammatory cytokines, like caspase- 1 dependant IL1 $\beta$, typeI IL receptor (IL1R1), and IL1 receptor antagonist (IL1Ra) are all important regulators of the IL1 signaling complex, which plays important role in inflammation [10]. IL1 $\beta$ maturation is dependent on caspase-1 (Casp-1) activation. The pathogenic role of IL1 signaling is found to the inflammasome activation through Toll like receptor homology domain in liver resident Kupffer cells [13].

Till date there is no relevant treatment option available for NASH except obesity management through change in food habit. Among drugs tried in NAFLD, Metformin in open label studies, proved to be effective in improving liver biochemistry, but did not result in improvement of fibrosis showed in a small study of patients with NASH [13]. A large scale study is needed to establish whether metformin has any protective role in patients with NAFLD or NASH [13]. Glitazones improved insulin sensitivity by acting as selective agonist of the nuclear peroxisome proliferator-activated receptor (PPAR) [14]. Small clinical trials involving glitazones in the management of NASH have shown a beneficial effect on liver histology (15). A more recent study of larger numbers of patients has suggested that pioglitazone does not have a significant modulatory effect on liver fibrosis in patients with NASH [16] with reduction in steatosis and inflammation [17]. The drug Statin along with Vitamin E is effective in reducing weight to a modest degree (5-10 percent) and improved lipid profiles [18]. Among other treatment options Incretin like molecule Glucagon-like peptide-1 (GLP-1) is the most important one. Its receptor agonist and inhibitors of dipeptidyl peptidase-4 (DPP-4) are used in treatment of type 2 diabetes mellitus. DPP-4 serum activity and hepatic expression are shown to be elevated in several hepatic diseases [19]. There are several experimental and clinical trials exploring the efficacy of incretin based therapies in NAFLD treatment [20]. They suggest that GLP-1 analogues might have beneficial effect on hepatic steatosis acting as insulin sensitizers and directly by stimulating GLP1 receptors expressed on hepatocytes. The use of DPP-4 inhibitors also results in hepatic fat reduction but the mechanism of action remains unclear [21].

Despite the abundance of clinical trials, NAFLD therapy remains a challenge for the scientific community, and there are no licensed therapies for NAFLD [22, 23]. Urgently, new pharmacological approaches are needed. Here, we will focus on the challenges facing actual therapeutic strategies and the most recent investigated molecules [24, 25].

In this study, we present new insights into delineating the role of IL1ßeta and its receptor antagonist in promoting and antagonising inflammatory response in NASH including macrophage activation and lipotoxicity, resulting in deposition into or translocation of fat pool from hepatocyte.
We used the extracellular inflammatory molecules isolated from THP1, a human monocytic cell line macrophages, known to produce proinflammatory cytokine IL1 beta and IL1 receptor antagonist. The study was conducted to find the importance of recombinant inflammatory cytokine from a different cellular source of human origin and to explore its possible therapeutic use in the modulation of inflammatory signaling pathways for the treatment of NASH.

\section{Materials and Method}

\subsection{Cell Culture}

\subsubsection{HepG2}

HepG2 cells were cultured in DMEM supplemented with $15 \%$ fetal calf serum and $50 \mu \mathrm{g} / \mathrm{ml}$ gentamicin and a subculture was maintained every 4 to 6 days.

\subsubsection{THP1 Monocyte Culture and Macrophage Differentiation}

Suspended THP-1 cells were cultured in RPMI 1640 with $10 \%$ FBS and supplemented with Penstrep. When the cells reached a confluency of 50-60\% they were treated with 5, 20 and $50 \mathrm{ng} / \mathrm{ml}$ Phorbol Myristate Acetate (PMA) (TOCRIS) and incubated for 24 to $48 \mathrm{hrs}$ allowing it to get attached and differentiate into macrophages. The macrophages were treated with Lipopolysaccharide (LPS) $(100 \mathrm{ng} / \mathrm{ml})$ for $3 \mathrm{hrs}$, then LPS was removed, cells were washed and incubated for $24 \mathrm{hr}$ to collect the supernatant $[13,23,26,27]$. The supernatant may also be denoted as Soup or conditioned media (CM).

\subsection{High Performance Liquid Chromatography - HPLC}

The THP-1 supernatant was eluted by reverse-phase HPLC using $\mathrm{m}$ bondapack, $\mathrm{C} 18$ column (Waters Associates) with flow rate of $1 \mathrm{~mL} / \mathrm{min}$, using Acetonitrile: water (1:1) as mobile phase and applying a gradiant following a previous method [28, 29]. The purified compounds were first concentrated in vacuum evaporator and detected for the presence of IL1B and IL1Ra in an antibody ELISA reader [3, 6].

\subsection{Free Fatty Acid Preparation for Cell Treatment}

For preparing Bovine Serum Albumin (BSA) conjugated free fatty acid (FFA), $0.2 \mathrm{mM}$ palmitic acid (Sigma) stocks were prepared in ethyl alcohol and subsequently conjugated with fatty acid free BSA (20\% in Kreb's Ringer solution) by shaking the mixture at $37^{\circ} \mathrm{C}$. Palmitic acid was mixed with BSA and shaken in a $37^{\circ} \mathrm{C}$ incubator. After filtration the sterile mixture was cooled to room temperature and stored at $-20^{\circ} \mathrm{C}$ for further use. BSA conjugated Palmitic Acid (PA) was treated at three different concentration: $100 \mathrm{mM}, 200 \mathrm{mM}$ and $500 \mathrm{mM}$ [12].

\subsection{Treatment of Cells with FFA and Cell Supernatant Extracts}

HepG2 Cells (80-90\% confluency) were treated overnight either with BSA conjugated palmitic acid in normal and serum free media. Harvested Cells were collected in cell lysis 
buffer adding protease and phosphatase inhibitor (Sigma) $[12,15]$. The extract from THP-1 supernatant will be denoted as THP1 and the differentiated macophage supernatant extract will be denoted as Mac for treatment abd experimental purpose.

\subsection{Cell Lysis and Immunoblotting}

HepG2 cells were cultured on 6-well dishes to $80-85 \%$ confluency and stimulated with $500 \mu \mathrm{M}$ FA Free/1\% BSAPA for $24 \mathrm{~h}$ or with IL1ßeta/ IL1Ra (prospec) at different concentrations of $20 \mathrm{pg} / \mathrm{ml}$ after optimization. At indicated time points, the cells were washed in PBS and lysed in icecold lysis buffer [1 (M) Tris $\mathrm{HCl}$ pH 7.4, 5 (M) NaCl, 1\% Triton X-100, 1.5m (M) EDTA and 1.5m (M) EGTA]. The cells were lysed on ice for $1 \mathrm{hr}$ and centrifuged at 12,000 rpm for $10 \mathrm{~min}$ at $4^{\circ} \mathrm{C}$ with with protease and phosphatase inhibitor tablets (Roche, Basel, Switzerland). Total Protein concentration was measured from the cell lysate using BCA Protein reagent kit (Thermo) in an ELISA reader. Equal amount of proteins were separated by SDS-PAGE, transferred to PVDF membrane (EMD Millipore), and visualized with enhanced chemiluminescence using Western HRP Lumina substrate (EMD Millipore). Images were taken in the Chemi documentation system (Bio-Rad, Hercules, CA, USA) [12, 24, 25].

THP1 cells were analyzed for the extent of cell adherence, the surface marker of macrophages, and checked for stable differentiation without undesirable gene upregulation. Once the cells were properly attached PMA was washed and fresh media was added for another 48 hours. The Final conditioned media was collected, tested for its various cytokine contents and used to treat the HepG2 cells under different treatment conditions i.e. control or high fat induced [13].

\subsection{ATGL Expression, Knockdown, Plasmids, Transfections and ShRNA Adenovirus}

ATGL (mouse variant 1) cloned in pQTri-HA vector obtained as a gift from Dr. Partha Chakrabarti, IICB, Kolkata. ATGL was transfected and cloned in plasmids pcDNA 3.1 (2) myc-his vector using the forward primer 5'TCACCTCGAGATGTTCCCGAGGGAGACCAAGTGG-3' and reverse primer 5'TAGAAGCTTGGGCAAGGCGGGAGGC-CAGGTGGATC3' containing Xhol and HindIII restriction sites, respectively. ATGL was knocked down transfecting the shRNA sequence 5'-TGTAATGATGGGCCCTAAT-3'using Lipofectamine 2000 reagent (Thermo Fisher Scientific) according to the supplier's instructions in HepG2 cells with 70-80\% confluency. Adenovirus carrying short hairpin RNA (shRNA) against mouse ATGL was generated using the BlockIt Adenoviral RNAi Expression kit (Thermo Fisher Scientific) and purified using the Fast-Trap virus purification and concentration kit (EMD Millipore, Billerica, MA, USA) [25].

\subsection{Quantitative Real-Time PCR}

Total cellular RNA was isolated using Trizol (Thermo
Fisher Scientific), and cDNA was prepared by using reverse transcriptase enzyme (Bio-Rad) and quantified in Nanodrop sectrophotometer (Thermo). The gene expression was quantified by SYBR Green (Roche) via Light Cycler 96 realtime PCR (Roche, Basel, Switzerland) in triplicate. Gene expression was normalized by 18SRNA and GAPDH invariant control expression [26, 27].

\subsection{Lipid Metabolism Study}

\subsubsection{Lipolysis Assay}

HepG2 cells were incubated in DMEM with $2.5 \%$ fatty acid-free bovine serum albumin for $2 \mathrm{~h}$ at $37^{\circ} \mathrm{C}$ with and without $8 \mu \mathrm{M}$ isoproterenol. Glycerol content and nonesterified fatty acid in the media was measured colorimetrically using the commercially available kits against a set of glycerol and FA standards. Cells were washed with cold PBS and lysed in 1\% Triton X-100 buffer, and the protein concentration was determined and used to normalize glycerol release. All the experiments were carried out in triplicates [25].

\subsubsection{Lipogenesis Assay}

De novo lipogenesis in HepG2 was assayed according to the protocol of Sanyal et al. [28]. Briefly, cells were serum starved for $2 \mathrm{~h}$, followed by incubation with $0.6 \mathrm{mCi}$ of $[1,2$ ${ }^{14} \mathrm{C}$ ] sodium acetate (BRIT) for $1.5 \mathrm{~h}$. Total intercellular lipids were extracted using a hexane:propanol (4:2 vol/vol) solution. The incorporation of $\left[1,2{ }^{14} \mathrm{C}\right]$ acetate (sp Activity, $46 \mathrm{mCi} / \mathrm{mmol})$ in the lipid phase was assayed by scintillation counting.

\subsubsection{TG Assay}

The amount of TGs was measured using the Triglycerides assay Kit (Hind Biotek). Briefly, cells were treated with Palmitate and or BSA for $24 \mathrm{~h}$. One hour after the palmitate treatment, the cells were treated with $100 \mathrm{mM}$ fenofibrate for $24 \mathrm{~h}$. Cells were washed with PBS, and lysed in $0.5 \%$ PBSTritonX-100. The cells were then centrifuged at $16,000 \mathrm{~g}$ at $4^{\circ} \mathrm{C}$ for $15 \mathrm{~min}$. A total of $25 \mathrm{ml}$ of the lysate was added to $100 \mathrm{ml}$ of the TG reagent, and $2 \mathrm{ml}$ of the TG standard (100 $\mathrm{mg}$ ) was used and kept for $5 \mathrm{~min}$ at $37^{\circ} \mathrm{C}$ in the dark and measured at $505 \mathrm{~nm}$ using the Synergy H1 Hybrid reader (BioTekInstruments, USA). It was normalized by the protein concentration $[24,25,27]$.

\subsubsection{Fatty Acid Oxidation (FAO)}

HepG2 cells were grown in six well plate to $90 \%$ confluency. The cells were treaed overnight as required and then undergone a $2 \mathrm{hr}$ fasting before adding the radioactive palmitatebound to FA free BSA, which was incubated for another $2 \mathrm{hr}$, the $\mathrm{CO}_{2}$ release was captured through carbonate formation in $\mathrm{NaOH}$ coated adsorbant paper and counted in a beta counter $[24,25]$.

FAO was measured as previously described [30], with minor modifications. Briefly, cells were serum starved for $2 \mathrm{~h}$ and treated either with $1 \mathrm{mCi}$ of $\left[1-{ }^{14} \mathrm{C}\right]$ palmitate (Brit, Mumbai, India) (Sp. Actvity: $40 \mathrm{mCi} / \mathrm{mmol}$ ) for $2 \mathrm{~h}$. After incubation, $70 \%$ perchloric acid was added to each well, and 
the $\mathrm{CO}_{2}$ released was trapped in Whatman paper soaked in 3 (M) $\mathrm{NaOH}$ for $1 \mathrm{hr} .{ }^{14} \mathrm{C}$ levels were estimated using a scintillation counter (PerkinElmer) [28, 29].

\subsubsection{Microscopy - Oil Red O Test for Fat Deposition Assay}

The fat deposition in Treated HepG2 cells were qualitatively determined by conventional Oil Red O (Sigma Aldrich) test in triplicate. The cells were first formalin fixed and stained with freshly prepared Oil Red $\mathrm{O}$ working solution for 10 mins following the standard protocol [28]. Nuclei were lightly stained with $5 \%$ hematoxylin for contrast. The cells were observed under microscope for lipid droplet deposition assay $[27,30]$.

\subsection{Statistical Analysis}

All values are represented as means \pm S.D. of the indicated number of measurements. A one-way variance analysis was used to determine the significance, with $\mathrm{p}<0.05$ for acquiring statistically significant data.

\section{Results}

\subsection{Determination of Macrophage Response of the Differentiated THP1 Cells}

Suspended THP1 cells were differentiated into macrophages using PMA. On differentiation the cells becomes well attached to the surface. The most optimum differentiation condition was found to be $24 \mathrm{hr}$ treatment with 50ng/ml PMA followed by $24 \mathrm{hr}$ incubation withot PMA. Figure 1 shows that the level of $i$ NOs and CD11b expressions gets increased on differentiation.

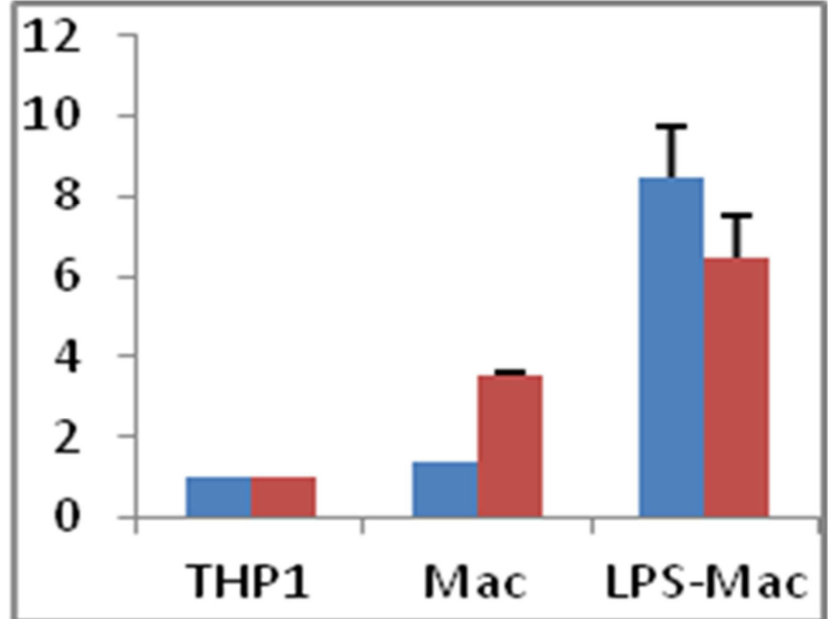

Figure 1. Expression levels of $C D 11 b$ and $i N O s$ increases as a result of THP1 differentiation into macrophages by the action of PMA.

\subsection{HPLC and Isolation of Purified Product from THP1 and Macrophagic Soup}

The THP1 and macrophagic soup was passed through an analytical C-18 HPLC column, for purification, isolation and identification of its components. The components were tested for presence of IL1ßeta IL1Ra. The components were isolated by a gradient mentioned in the previous article [28, 29]. Eluate at Rt 16.3 minute from Mac soup (Figure 2d) and eluate at Rt 20.9 minute from THP1 soup (Figure 2c) were found to show positive results for IL1 $\beta$ and IL1Ra respectively in ELISA. The purified components were vacuum dried, lyophilised and used for treating HepG2 cells. Recombinant IL1ßeta (prospec) and IL1Ra were also eluted through the same column at an Rt value of 13.11 minute (Figure 2a) and 18.1 respectively (Figure 2b). A difference was observed between the elusion characteristics of macrophagic interleukin and purchased IL1 $\beta$ used as a standard.

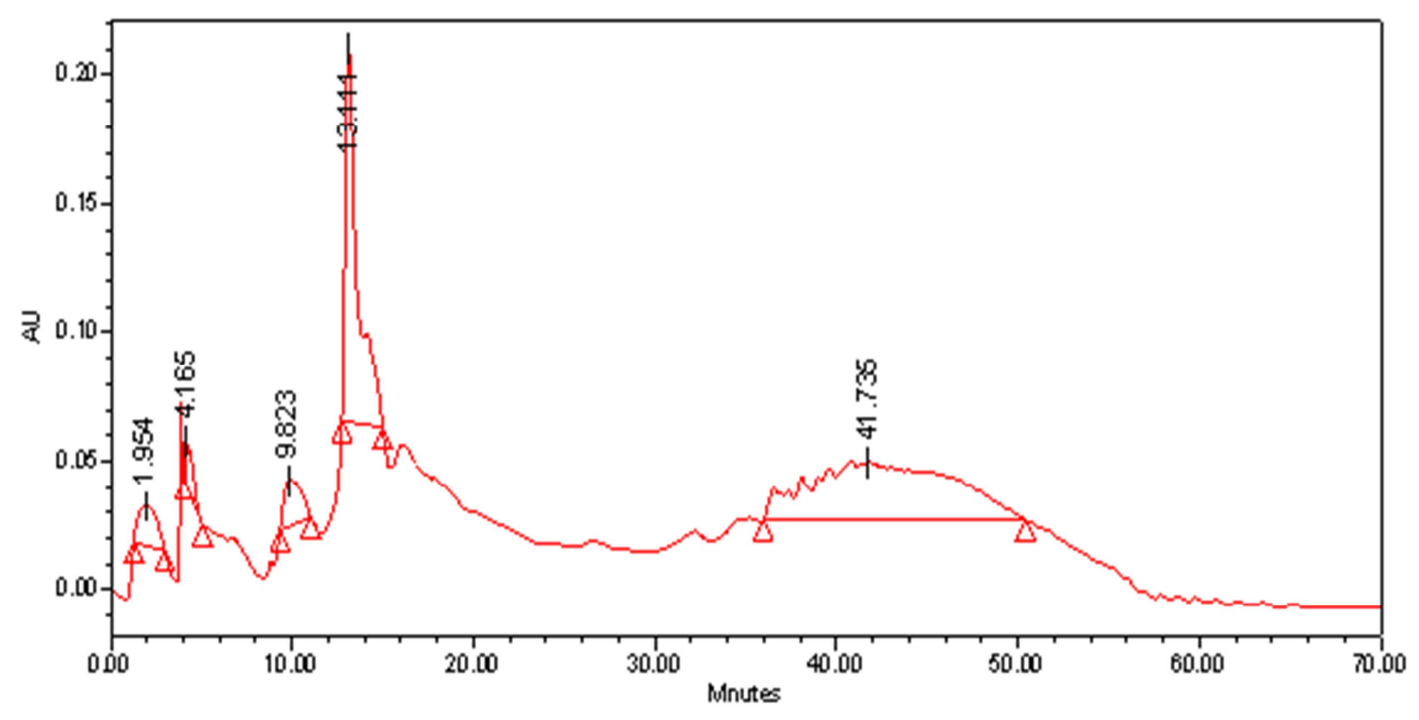




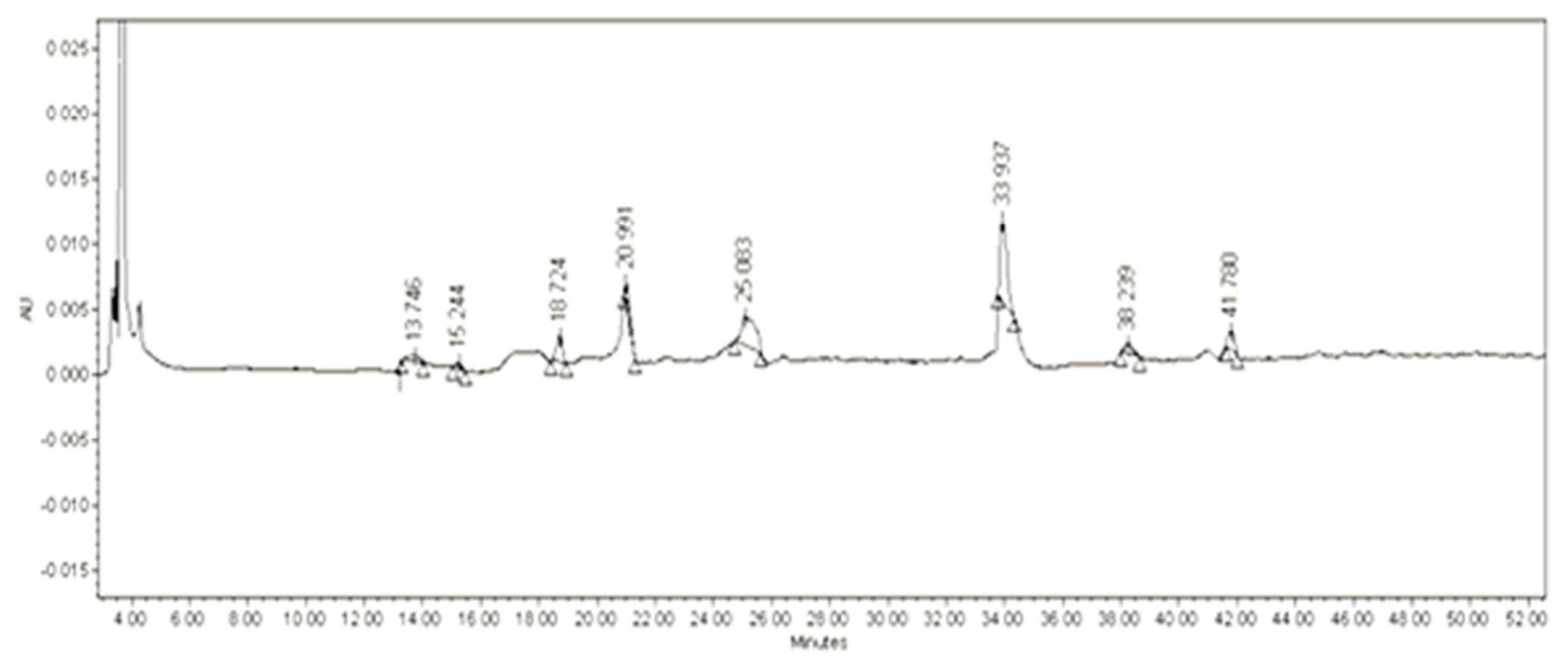

(b)

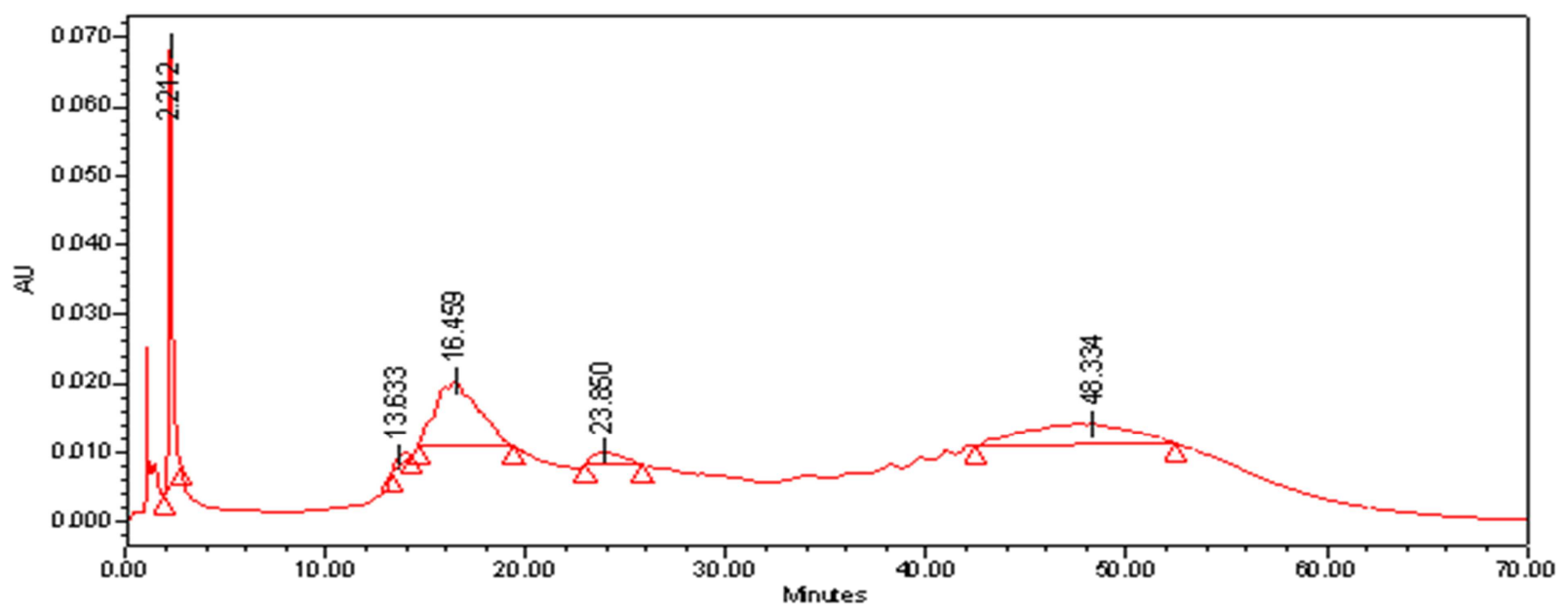

(c)

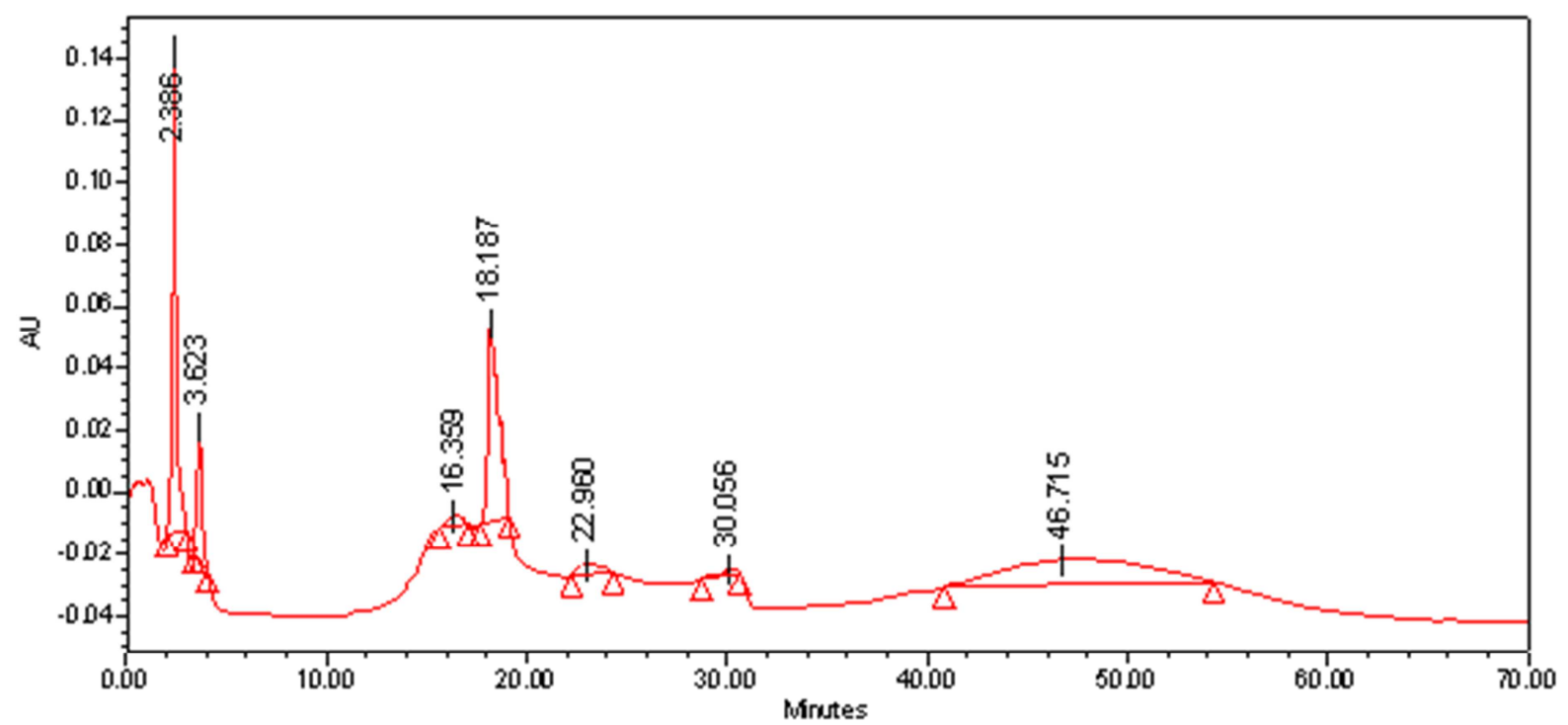

(d)

Figure 2. Analysis of (a)IL1 (b)IL1Ra (c)Macrophage CM and (d)THP1-CM through High performance liquid chromatography. 


\subsection{Oil Red O}

The oil Red $\mathrm{O}$ results are showing a clear difference in accumulation nature of fat in HepG2 as a result of different treatment conditions. Figure $3 \mathrm{a}$ is showing normal fat accumulation at control condition. Saturated fatty acid Palmitate PA $(200 \mathrm{mM})$ was used as a standard for studying the fat accumulation (Figure $3 \mathrm{~b}$ ) for $24 \mathrm{hrs}$. In a separate observation it was found that treatment with only recombinant IL1 $\beta$ increases (Figure 3c) and IL1Ra reduces fat level (Figure 3d and 3e). Recombinant IL1Ra brings down the accumulation level lower than normal. IL1 $\beta$ exaggerates fat accumulation when treated consecutively with PA (Figure 3f) and reduced with combination PA and IL1Ra (Figure 3g). Similar effect was observed with Mac, i.e. accumulation (Figure 3h), while an opposite phenomenon i.e. fat reduction was observed with THP1 (Figure 3i). Similarly when extract from THP1 soup was added with PA the accumulated fat was found to get removed (Figure 3j) while with Mac it was found to increase to some extent (Figure 3k). Fat accumulation with PA was increased in both of the cases IL1 $\beta$ and Mac while decreases both with IL1Ra and THP1 soup extract.
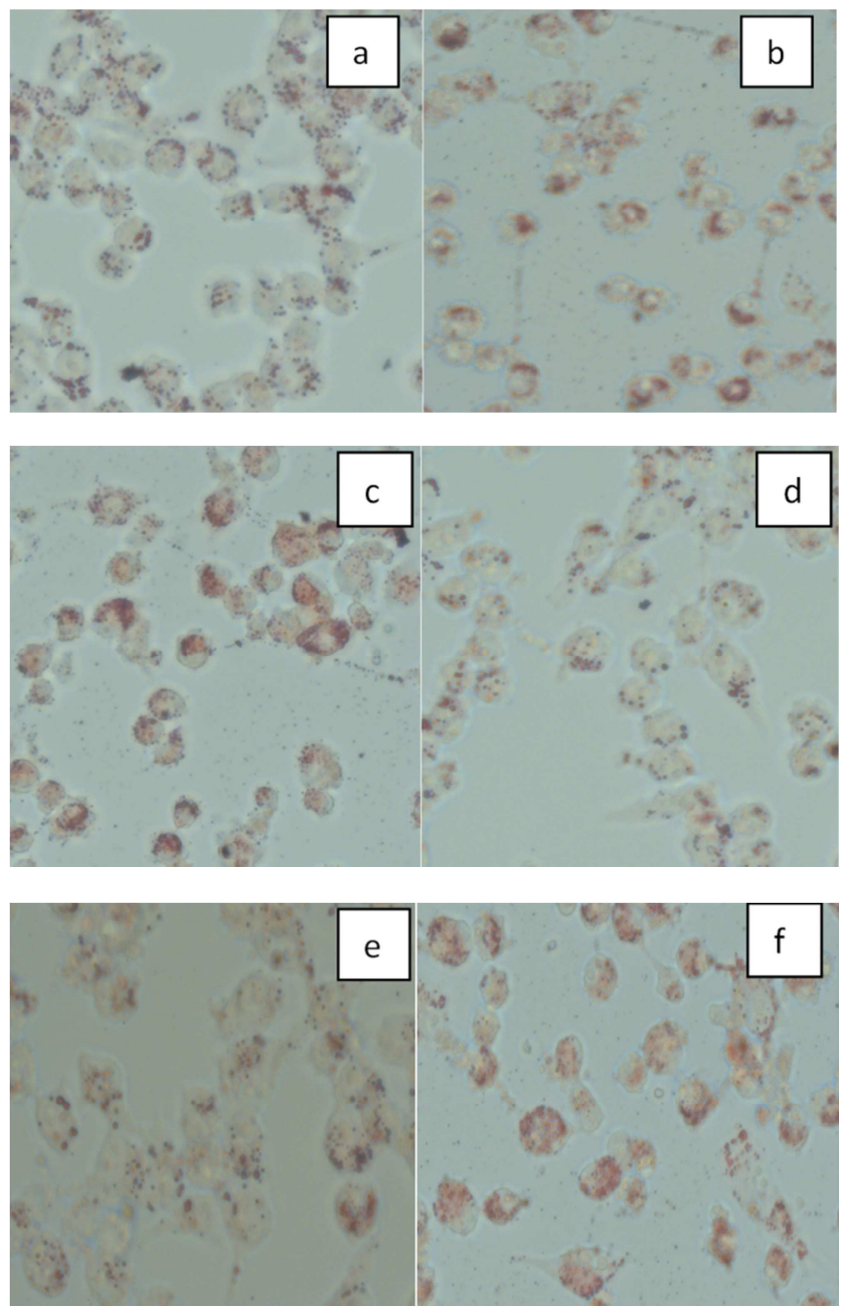
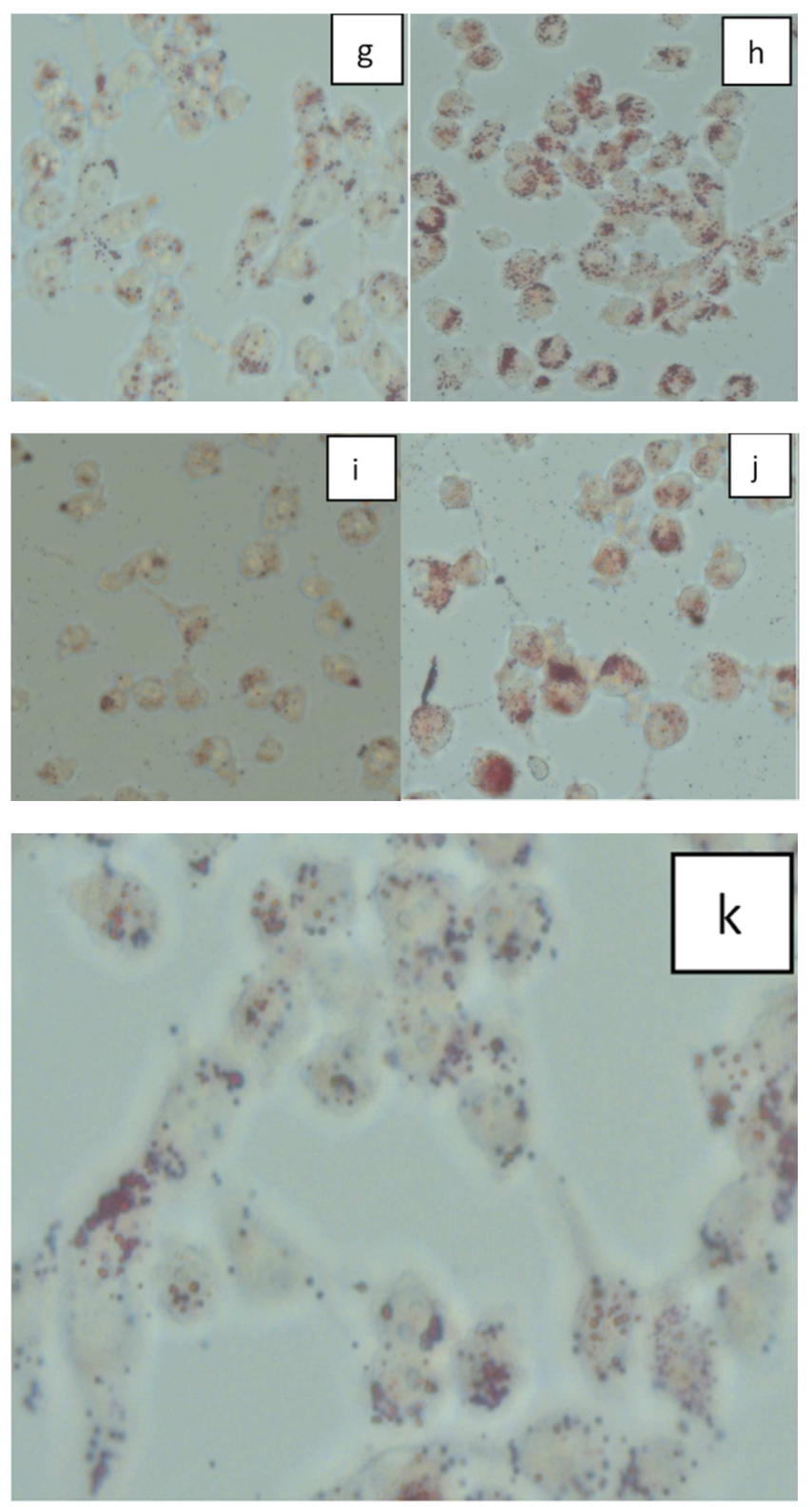

Figure 3. Effect of treatment conditions (a) Con (b) PA (c) ILI ( d) ILIRa (e) ILI $\beta+I L 1 R a$ (f) ILI $\beta+P A$ (g) ILIRa+PA (h) Mac (i)THPI (j) PA+Mac (k) PA+THP1 in HepG2 cells detected by Oil red $O(M=20 X)$.

\subsection{TG Assay, Lipolysis and Lipogenesis, and Fatty Acid Oxidation}

Figure 4 shows increased fatty acid oxidation in HepG2 cells in IL1Ra and THP1 treated cells while it decreases with IL1 $\beta$ or Mac treatment. The rate of FAO increases with increasing concentration of IL1Ra (Figure 4a). Accumulation of intracellular TG increases with the action of PA, IL1 $\beta$ while with IL1Ra much change was not found. Recombinant IL1Ra also increases lypolysis sharply with an effect in sharp decrease in lipogenesis (data not shown). THP1 and Mac treatment gives similar observations i.e. THP1 behaves like IL1Ra and Mac behaves like IL1ß. 


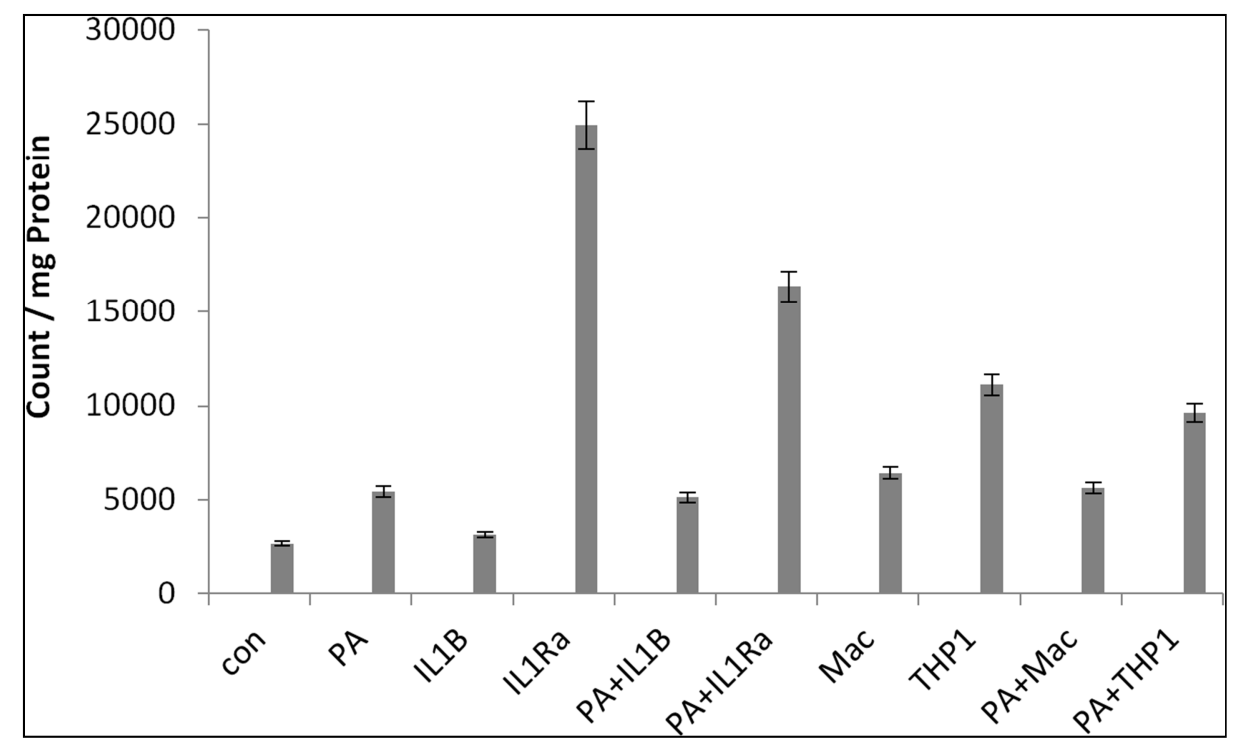

Figure 4. Fatty Acid Oxidation in HepG2 in different treatment conditions.

\subsection{Insulin Sensitivity of THP1, Mac and Interleukin Treatmet}

Figure 5a and Figure 5b shows Phospho AKT and Total AKT expression levels under different treatment condition. PA and IL1 $\beta$ treatment reduces pAKT levels (Figure 5a) expresses insulin resistance while the IL1Ra is not showing such evidences (Figure 5a). THP1 treatment shows to be non reactive to pAKT and the effect of Mac on pAKT is very negligible (Figure 5b).
Con
IL1Ra
IL1 beta
PA

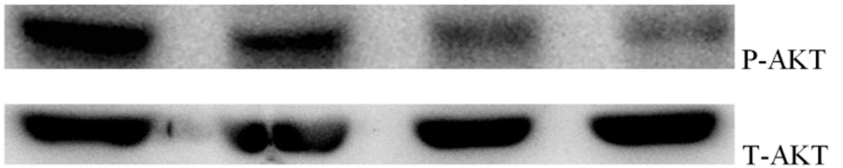

(a)
Con
THP1
$\mathrm{Mac}$

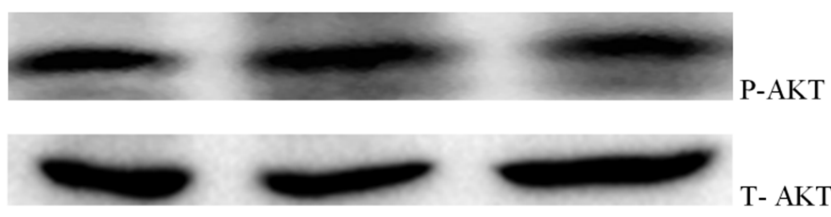

(b)

Figure 5. Insulin resistance analysis with different treatment conditions.

\subsection{RNA Isolation and QPCR Fatty Acid Metabolic Genes}

Protein levels of lipid metabolic genes like ACC1, CPT1alpha, ASCL, PPargamma and HSL were observed (Figure 5). It was found that the expression levels of the genes related to FAO were enhanced with the actibvity of IL1Ra or THP1. And it was lowered with the extract of MAC, and IL1 $\beta$. The treatment of IL1Ra markedly increased ACSL and Cpt1 Alpha level.

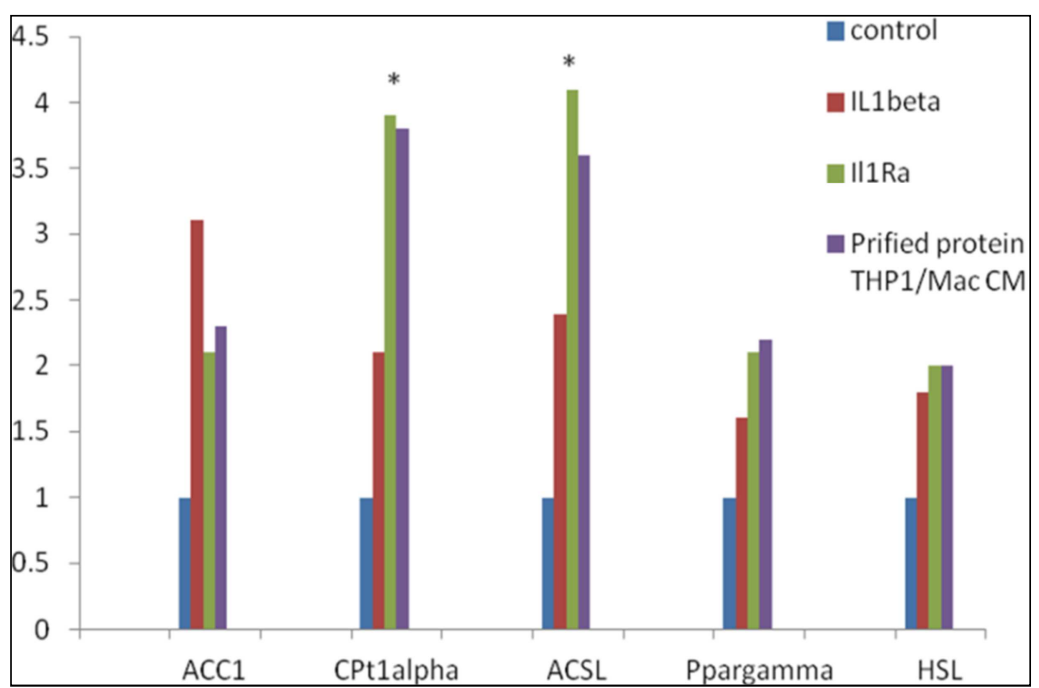

Figure 6. Expression of QPCR fatty acid metabolic genes. 


\subsection{The Interleukin Functions Dependant on ATGL Activity}

SiATGL or ATGL overexpressed (ATGLox) HepG2 cells when treated with recombinant IL1 $\beta$ or its antagonist and also the THP1 and Mac the fatty acid oxidation is markedly suppressed in SiATGL HepG2 cells, while it increases with PA treatment (data not shown).

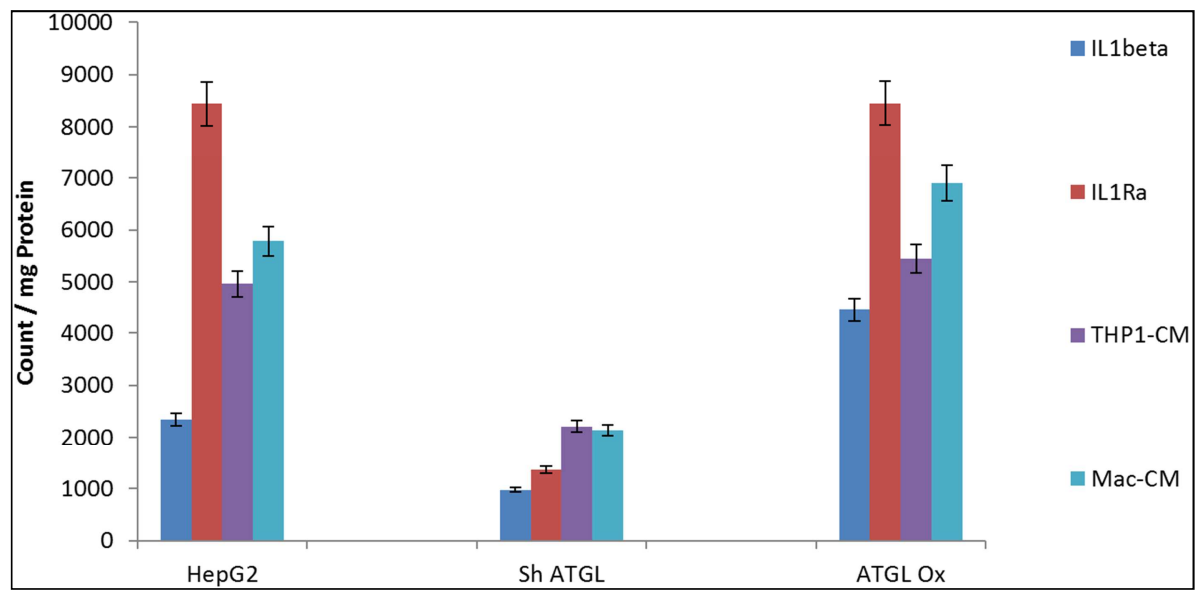

Figure 7. Fatty acid metabolism in liver is ATGL dependant.

\section{Discussion}

THP1 a human monocytic cell line was grown on RPMI media and differentiated into macrophage by Using a phorbol myristate acetate (PMA)-induced cell differentiation model $[6,8]$. Inflammatory markers like iNOs and differentiation marker CD11b were expressed typically by macrophages on differentiation [6]. After differentiation Macrophage (MAC) was treated with LPS for $3 \mathrm{hrs}$. LPS treatment leads to stimulation of the cell and activation of TLR pathway [31]. This helps to stimulate the inflammosome, which leads to activation and maturation of procaspase into caspase 1 and produces interleukins. On differentiation the monocytes which were grown and maintained on a suspended culture were subjected to be anchored on the plate surface. For differentiation the cells were treated with different PMA concentrations for 24 to $48 \mathrm{hrs}$. Most optimum result was found with a PMA concentration of 50nm $24 \mathrm{hr}$ treatment. After $24 \mathrm{hr}$ PMA was removed and cells were replenished with fresh media and incubated overnight. After 3 hrs LPS stimulation, the cells were washed and incubated for another $24 \mathrm{hrs}$. The macrophagic soupernatant Mac was collected after this stage and used for rest of the experiment.

LPS treatment leads to stimulation of macrophages which helps to generate IL1 $\beta$ through NFKB pathway. Both THP1 and Mac soup was purified by gradient HPLC. IL1ßeta was detected by ELISA. IL1 $\beta$ was found more concentrated in the Mac soup. IL1 $\beta$ and, IL1Ra were isolated at the retention time of 16.4 or 18.1 minutes respectively. Recombinant IL1 $\beta$ and THP or Mac isolated interleukins are close in nature but may not be similar. They showed closer molecular mass in ESI MS/MS analysis. Since in case of Mac soup and THP1peptides the retention times are relatively close, thus ELISA was performed to confirm the presence IL1 $\beta$ [32].

Purified products from LPS stimulated Macrophage supernatant and monocyte supernatant were used for further treatments. Confluent $(80 \%)$ HepG2 cells were treated with the two purified products simultaneously from the monocyte and macrophage soup [33]. This shows accumulation of fat occurs in case of PA, IL1 $\beta$ and Mac soup treatment. On the other hand treatment of IL1 $\beta$ and THP1 soup extract resulted in removal of the accumulated fat. While a concurrent treatment with PA and IL1 $\beta$ or Mac increases the level of accumulation to a higher extent, the other treatments (IL1 $\beta$ and THP1) helps to reduce the fat acuumulation which was developed by PA itself. Treatment with only recombinant Ill $\mathrm{Ra}$ reduces the fat level drastically. It was observed that the rate of fatty acid oxidation was also changed during this treatment accordingly.

Treatment with recombinant IL1Ra increases the rate of beta oxidation drastically shown in Figure 4. The combined treatment condition with both IL1Ra and IL1 $\beta$ increased the beta oxidation rate. The Figure $4 \mathrm{a}$ and $4 \mathrm{~b}$ shows how fatty acid oxidation changes in two different treatment condition. Figure $4 \mathrm{a}$ shows the treatment with standard recombinant IL1RA and IL1 $\beta$ and Figure $4 \mathrm{~b}$ shows the treatment results of THP1 and macrophage soup. In both the figure a substantial change in the fatty acid oxidation level was observed on treating the cells with recombinant IL1Ra. With an increase from $20 \mathrm{ng} / \mathrm{ul}$ conc of IL1Ra to $100 \mathrm{ng} / \mathrm{ul}$ the level of beta oxidation increases almost twice its control value. Lipogenesis is found to increase with IL1 $\beta$ or Mac treatment comparable to PA treatment [34, 35] and lipolysis decreases. The lipolysis is increased with IL1Ra. Such evidences were found in liver resident macrophages notified in a prior atricle [36, 37].

Insulin sensitivity was affected with IL1 $\beta$ when compared to treatment with PA and control. It was observed from Figure 5 that with IL1Ra treatment resulted into decrease of pAKt which is evidence to insulin resistance. But no substantial 
change was observed with IL1 $\beta$ or Mac soup [28, 29].

The beta oxidation activity of THP1 or Mac and their standard recombinant counterparts get affected by ATGL. To prove this HepG2 was transfected with SiATGL and ATGL overexpressing gene. It was observed that activity of IL1Ra and IL1 $\beta$ or the THP1 and Mac was affected and the betaoxidation level was decreased. It could not be improved even to the normal levels of respective treatment conditions. So it is evident that fat burning rate by interleutins depends on ATGL expression, evident from a previous work published [26, 35]. Different fat metabolic gene expressions were checked and results are showed that ACC, cptlalpha, HSL, ppargamma, ASCL, which are related to burning fat expression was increased with IL1Ra [36-38]. While the expression of HSL is not much changed, When the treatment condition changed from IL1 $\beta$ to IL1Ra.

\section{Conclusion}

Although IL1B is an inflammatory cytokine it might play an important role in accumulating fat in HepG2 cells. Higher levels of IL1Ra reduces the beta oxidation level. So this antiinflammatory molecules can be useful in reducing the TG levels in cell. The results show that treatment with IL1Receptor antagonist inhibits the IL1 $\beta$ activity but it also act as a strong inhibitor of ppar alpha antagonist. The same effect was also found with the THP1 soup which is already known to be reach in IL1 proteins with a major contribution of the Il1 receptor antagonist [6], treatment of which is also showing a lowering effect of accumulation of Triglyceride (TG) and increased beta oxidation in the cell.

Inflammatory response in HepG2 is not a very natural phenomenon. As because HepG2 is not an Inflammatory cell. But we have found that a parenchyma tissue may also response differently in presence of inflammatory attack. Sometimes Chronic inflammation leads to some changes in their behaviour as reported by previously [40]. So inflammatory exposure may act like a stress which may lead to some unusual change and damage of normal tissue. Here both the IL1 $\beta$ and the receptor antagonist is showing their effect on fatty acid oxidation (FAO) and leads to some newer changes in the HepG2 cell [8].

Consistent with these results, several other studies have also observed that hepatic ATGL overexpression or deletion affects FA oxidation but not VLDL secretion in vitro and in vivo [2, 3]. Similar effects of ATGL on channeling hydrolyzed FAs to $\beta$-oxidation have also been observed in adipocytes, small intestine, and myocardial tissue [38]. The mechanism through which ATGL channels FAs hydrolyzed at the surface of lipid droplets (LDs) to the mitochondria, however, is unknown. In this article also the exact mechanism is not established which can be taken into account for future experiments. Till date no such observation is found with the IL1Ra and thus the work can be further extended to open a newer area.

So it can be further studied whether the antagonist which is anti-inflammatory in nature, can be used as a potential anti- inflammatory drug in a very regulated dosage for the patients suffering from the fatty liver condition where inflammation is one of the important attribute. It can be used as antiinflammatory as well as aTG reducing agent. Without affecting the liver insulin sensitivity, it becomes an added advantage to weight management [28].

\section{References}

[1] Younossi, Z. M., Stepanova, M., Afendy, M., Fang, Y., Younossi, Y., Mir, H. and Srishord, M (2011). Changes in the prevalence of the most common causes of chronic liver diseases in the United States from 1988 to 2008. Clin Gastroenterol Hepatol 9, 524-530.

[2] Cohen, J. C., Horton, J. D. and Hobbs, H. H (2011). Human fatty liver disease: old questions and new insights. Science $332,1519-1523$.

[3] Sozio, M. S., Liangpunsakul, S. and Crabb, D (2010). The role of lipid metabolism in the pathogenesis of alcoholic and nonalcoholic hepatic steatosis. Semin Liver Dis 30, 378-390.

[4] Nobili, V., Cutrera, R., Liccardo, D., Pavone, M., Devito, R., Giorgio, V., Verrillo, E., Baviera, G. and Musso, G (2014). Obstructive sleep apnea syndrome affects liver histology and inflammatory cell activation in pediatric nonalcoholic fatty liver disease, regardless of obesity/insulin resistance. Am J Respir Crit Care Med 189, 66-76.

[5] World Gastroenterology Organisation Global Guidelines. Nonalcoholic fatty liver disease and nonalcoholic steatohepatitis 2012 .

[6] Mathews, S. and Gao, B. (2013). Therapeutic Potential of Interleukin 1 Inhibitors in the Treatment of Alcoholic Liver Disease. Hepatology 57 (5), 2078-2080.

[7] Kugelmas, M., Hill, D. B., Vivian, B., Marsano, L. and McClain, C. J: Cytokines and NASH: a pilot study of the effects of lifestyle modification and vitamin E. Hepatology (2003) (38), 413-419.

[8] Abiru, S., Migita, K., Maeda, Y., Daikoku M., Ito, M., Ohata, K., Nagaoka, S., Matsumoto, T., Takii, Y., Kusumoto, K., et al (2006). Serum cytokine and soluble cytokine receptor levels in patients with non-alcoholic steatohepatitis. Liver Int 26, 39-45.

[9] Jarrar, M. H., Baranova, A., Collantes, R., Ranard, B., Stepanova, M., Bennett, C., Fang, Y., Elariny, H., Goodman, Z., Chandhoke, V., et al (2008). Adipokines and cytokines in non-alcoholic fatty liver disease. Aliment Pharmacol Ther 27, 412-421.

[10] Copaci, I., Micu, L. and Voiculescu, M (2006). The role of cytokines in non-alcoholic steatohepatitis. A review. J Gastrointestin Liver Dis 15, 363-373.

[11] Zechner, R., Kienesberger, P. C., Haemmerle, G., Zimmermann, R., Lass, A (2009). Adipose triglyceride lipase and the lipolytic catabolism of cellular fat stores. J Lipid Res $50,3-21$.

[12] Grønning-Wang, L. M., Bindesbøll, C. and Nebb H. I (2007). The Role of Liver X Receptor in Hepatic de novo Lipogenesis and Cross-Talk with Insulin and Glucose Signaling. IN: Baez RV, editor. Lipid Metabolism. Mol Biosyst 3, 608-619. 
[13] Kirovski, G., Dorn, C., Huber, H., Moleda, L, Niessen, C., Wobser, H., Schacherer, D., Buechler, C., Wiest, R. and Hellerbrand, C (2011). Elevated systemic monocyte chemoattractrant protein-1 in hepatic steatosis without significant hepatic inflammation. Exp Mol Pathol 91, 780 783.

[14] Ratziu, V., Massard, J., Charlotte, F., Messous, D., ImbertBismut, F., Bonyhay, L., Tahiri, M., Munteanu, M., Thabut, D, Cadranel, J. F., et al (2006). Diagnostic value of biochemical markers (FibroTest-FibroSURE) for the prediction of liver fibrosis in patients with non-alcoholic fatty liver disease. BMC Gastroenterol 6, 6 .

[15] Nelson, A., Torres, D. M., Morgan, A. E., Fincke, C. and Harrison, S. A (2009). A pilot study using simvastatin in the treatment of nonalcoholic steatohepatitis: A randomized placebo-controlled trial. J Clin Gastroenterol 43, 990-994.

[16] Antonopoulos, S., Mikros, S., Mylonopoulou, M., Kokkoris, S. and Giannoulis, G (2006) Rosuvastatin as a novel treatment of non-alcoholic fatty liver disease in hyperlipidemic patients. Atherosclerosis 184, 233-234.

[17] Ekstedt, M., Franzén, L. E., Mathiesen, U. L., Holmqvist, M., Bodemar, G., and Kechagias, S (2007). Statins in nonalcoholic fatty liver disease and chronically elevated liver enzymes: a histopathological follow-up study. J Hepatol 47, $135-141$.

[18] Gómez-Domínguez, E., Gisbert. J. P., Moreno-Monteagudo, J. A., García-Buey, L., and Moreno-Otero, R (2006). A pilot study of atorvastatin treatment in dyslipemid, non-alcoholic fatty liver patients. Aliment Pharmacol Ther 23, 1643-1647.

[19] Foster, T., Budoff, M. J., Saab, S., Ahmadi, N., Gordon, C. and, Guerci, A. D ( 2011). Atorvastatin and antioxidants for the treatment of nonalcoholic fatty liver disease: the St Francis Heart Study randomized clinical trial. Am J Gastroenterol $106,71-77$.

[20] Eslami, L., Merat, S., Malekzadeh, R., Nasseri-Moghaddam, S. and Aramin, H (2013). Statins for non-alcoholic fatty liver disease and non-alcoholic steatohepatitis. Cochrane Database Syst Rev 12, CD008623.

[21] Musso, G., Gambino, R., Cassader, M. and Pagano, G (2011). Meta-analysis: natural history of non-alcoholic fatty liver disease (NAFLD) and diagnostic accuracy of non-invasive tests for liver disease severity. Ann Med 43, 617-649.

[22] Bugianesi, E., Pagotto, U., Manini, R., Vanni, E., Gastaldelli, A., de Iasio, R., Gentilcore, E., Natale, S., Cassader, M., Rizzetto, M., et al (2005). Plasma adiponectin in nonalcoholic fatty liver is related to hepatic insulin resistance and hepatic fat content, not to liver disease severity. J Clin Endocrinol Metab 90, 3498-3504.

[23] Hui, J. M., Hodge, A., Farrell, G. C., Kench, J. G., Kriketos, A., and George, J (2004). Beyond insulin resistance in NASH: TNF-alpha or adiponectin? Hepatology 40, 46-54.

[24] Langin, D (2006). Adipose tissue lipolysis as a metabolic pathway to define pharmacological strategies against obesity and the metabolic syndrome. Pharmacol Res. 53, 482-491.

[25] Castillero, E., Isabel Martı'n, A., Paz Nieto-Bona1, M., Ferna'ndez-Galaz, C., Lo' pez-Menduin, ${ }^{\sim}$ M., A' ngeles Villanu,' M., and Lo' pez-Caldero'n, A. (2012) Fenofibrate administration to arthritic rats increases adiponectin and leptin and prevents oxidative muscle wasting. Endocrine
Connections. 01, 1-12.

[26] Moncsek A., Al-Suraih M. S., Trussoni C. E., O'Hara S. P., Splinter P. L., Zuber C., Patsenker E., Valli P. V., Fingas C. D., Weber A., Zhu Y., Tchkonia T., Kirkland J. L., Gores G. J., Müllhaupt B., Nicholas F., LaRusso N. F., Mertens J. C. (2017) online. Targeting senescent cholangiocytes and activated fibroblasts with B-cell lymphoma-extra large inhibitors ameliorates fibrosis in multidrug resistance 2 gene knockout $\left(\mathrm{Mdr}^{-/-}\right)$mice Mertens. Hepatology. 67 (1), $247-$ 259.

[27] Hui-juan, L., Cheng-yu, Z., Fei, S., Ting, X., Jing, M., Qiang, Z., Cai-li Liang, S. L., Jing W., Zhang B., Yan-rong, L., Tao, S., and Zhou, H. G (2015). A Novel Partial Agonist of Peroxisome Proliferator-Activated Receptor $\gamma$ with Excellent Effect on Insulin Resistance and Type 2 Diabetes. Journal of Pharmacology and Experimental Therapeutics 353 (3), 573581 .

[28] Sanyal, A. J., Campbell-Sargent, C., Mirshahi, F., Rizzo, W. B., Contos, M. J., Sterling, R. K., Luketic, V. A., Shiffman, M. L. and Clore, J. N (2001). Nonalcoholic steatohepatitis: association of insulin resistance and mitochondrial abnormalities. Gastroenterology 120, 1183-1192.

[29] Chandra, S.. De K., Ganguly S., Sarkar B. and Misra M. (2009). Synthesis, radiolabeling and biological evaluation of a neutral tripeptide and its derivatives for potential nuclear medicine applications. Peptides 30, 2399-2408.

[30] Ferré, P (2004). The biology of peroxisome proliferatoractivated receptors: relationship with lipid metabolism and insulin sensitivity. Diabetes 53, S43-S50.

[31] Crespo, J., Cayón, A., Fernández-Gil, P., Hernández-Guerra, M., Mayorga, M., Domínguez-Díez, A., Fernández-Escalante, J. C. and Pons-Romero, F (2001). Gene expression of tumor necrosis factor alpha and TNF-receptors, p55 and p75, in nonalcoholic steatohepatitis patients. Hepatology 34, 11581163 .

[32] Haukeland, J. W., Damås, J. K., Konopski, Z., Løberg, E. M., Haaland, T., Goverud, I., Torjesen, P. A., Birkeland, K., Bjørob and K., Aukrust, P (2006). Systemic inflammation in nonalcoholic fatty liver disease is characterized by elevated levels of CCL2. J Hepatol. 44, 1167-1174.

[33] Klover, P. J., Zimmers, T. A., Koniaris, L. G., and Mooney, R. A (2003). Chronic exposure to interleukin-6 causes hepatic insulin resistance in mice. Diabetes 52, 2784-2789.

[34] Pradhan, A. D., Manson, J. E., Rifai, N., Buring, J. E. and Ridker, P. M (2001). C-reactive protein, interleukin 6, and risk of developing type 2 diabetes mellitus. JAMA 286, 327-334.

[35] Raubenheimer, P. J., Nyirenda, M. J. and Walker, B. R (2006). A choline-deficient diet exacerbates fatty liver but attenuates insulin resistance and glucose intolerance in mice fed a highfat diet. Diabetes 55, 2015-2020.

[36] Feldstein, A. E: Novel insights into the pathophysiology of nonalcoholic fatty liver disease (2010). Semin Liver Dis 30, 391-401.

[37] Wieckowska, A., Papouchado, B. G., Li, Z., Lopez, R., Zein, N. N. and Feldstein, A. E (2008). Increased hepatic and circulating interleukin-6 levels in human nonalcoholic steatohepatitis. Am J Gastroenterol 103, 1372-1379. 
[38] Jin, X., Zimmers, T. A., Perez, E. A., Pierce, R. H., Zhang, Z. and Koniaris, L. G (2006). Paradoxical effects of short- and long-term interleukin-6 exposure on liver injury and repair. Hepatology 43, 474-484.

[39] Miura, K., Yang, L., vanRooijen, N., Ohnishi, H. and Seki, E (2012). Hepatic recruitment of macrophages promotes nonalcoholic steatohepatitis through CCR2. Am J Physiol Gastrointest Liver Physiol 302, G1310-G1321.

[40] Brown, B. N., Ratner, B. D., Goodman, S. B., Amar, S. and Badylak, S. F (2012). Macrophage polarization: an opportunity for improved outcomes in biomaterials and regenerative medicine. Biomaterials 33, 3792-3802. 